\title{
Cognitive-Behavioral Psychotherapy, a Group Psycho-Educational Workshop and a Workshop for Caregivers of Sexually-Abused Children: a Case Study of Two Mexican Male Children
}

\author{
Rizo Martínez $\mathrm{LE}^{* 1}$ and Sánchez Sosa $\mathrm{JJ}^{2}$ \\ ${ }^{1}$ Maestría y Doctorado en Psicología con Orientación en Calidad de Vida y Salud, Departamento de Promoción, \\ Preservación y Desarrollo de la Salud, Centro Universitario del Sur, Universidad de Guadalajara, Colonia Centro, \\ Edificio G, planta baja, Ciudad Guzmán, Jalisco, México \\ ${ }^{2}$ Programa de Maestría y Doctorado en Psicología, Universidad Nacional Autónoma de México, Delegación Coy- \\ oacán, México
}

${ }^{*}$ Corresponding author: Rizo Martínez LE, Departamento de Promoción, Preservación y Desarrollo de la Salud, Maestría y Doctorado en Psicología con Orientación en Calidad de Vida y Salud, Centro Universitario del Sur, Universidad de Guadalajara, Av. Enrique Arreola Silva No. 883, Col. Centro, C.P. 49000, Ciudad Guzmán, Jalisco, México, Tel: +52 (341)575 2222, Ext:46168, E-mail: lucia.rizo@cusur.udg.mx, lucyrizomar@ hotmail.com

Citation: Rizo Martínez LE, Sánchez Sosa JJ (2018) Cognitive-Behavioral Psychotherapy, a Group PsychoEducational Workshop and a Workshop for Caregivers of Sexually-Abused Children: a Case Study of Two Mexican Male Children. J Case Rep Stud 6(2): 202. doi: 10.15744/2348-9820.6.202

Received Date: January 08, 2018 Accepted Date: April 25, 2018 Published Date: April 27, 2018

\begin{abstract}
It has been reported that a large percentage of men and women had experiences of sexual abuse during childhood the effects of which are determined by factors such as age, gender, characteristics of the experience, and cultural aspects, among others. In Mexico, only a limited number of sexual abuse cases are reported to the relevant authorities and even fewer receive adequate care and treatment. This article presents an evaluation of the effectiveness of an individualized cognitive-behavioral treatment involving a group psychoeducational workshop and a workshop for caregivers of two Mexican male children who had experienced sexual abuse. Clinical and cognitive evaluations, pre- and post-test treatment, and follow-up one-and-a-half years later were made. Differences between the two participants were found in all three evaluation periods. Various factors associated with these results are discussed.
\end{abstract}

Keywords: Male Children; Sexual Abuse; Treatment; Measurement; Mexico

\section{Introduction}

Several definitions of sexual abuse have been used in different studies and contexts. For our work, we adopted the approach of the World Health Organization (WHO), which defines this phenomenon as the involvement of children in sexual activity: 1) that they do not fully comprehend; 2) to which they are unable to give informed consent; 3) for which they are not developmentallyprepared; and 4) that violate a society's laws or social taboos. Child sexual abuse involves activities between a child and an adult -or another child- who, due to age or stage of development, occupies a position of responsibility, trust or power, that is intended to gratify or satisfy the needs of the latter. This may include, but is not limited to, inducing or coercing a child into engaging in unlawful sexual activity; the exploitative use of children in prostitution or other illegal sexual practices; and the exploitative use of children in pornographic performances and materials [1].

Reports on the prevalence of this phenomenon worldwide indicate that approximately $7.9 \%$ of males and $19.7 \%$ of females suffer some form of sexual abuse before the age of 18 [2]. While it is difficult to determine the real number of children and adolescents who are victimized sexually in Mexico, studies have found that less than $5 \%$ of children and adolescents evaluated reported having experienced sexual abuse [3,4], though one report found a prevalence of 18.7\% in adolescents [5], and Frías and Erviti (2014) reported that $6.82 \%$ of the young people they surveyed had experienced sexual abuse before age 18 [6]. All these authors, seconded by clinical and empirical information, argue that it is extremely difficult to determine real prevalences of sexual abuse in Mexico and other countries because it is often not disclosed due to the familistic and collectivist character of some of the cultures involved. A second factor is the limited nature of the legal protection of minors in Mexico, which means that few cases of sexual abuse are reported, and that when complaints do arise, the child or adolescent is usually removed from his family and sent to live in an 
orphanage. But those institutions do not always have the personnel and general conditions required for the healthy development of children. Worse yet, violence or negligence is common in those places.

These conditions leave much of Mexico's young population highly vulnerable to sexual abuse, while also causing feelings of resignation in these cases, since no one knows if it is better for children to continue in abusive situations in the family setting or risk putting them through legal processes that force them to relive the trauma and reside with strangers in environments just as undesirable as, or perhaps worse than, their home.

In addition, few victims ever receive professional psychotherapeutic care, and those who do often go to institutions where treatment is not focused on their specific problem. In this regard, clinical evaluations in Mexico are rarely prepared in for these cases, and when they are the approach is rarely adequate. Finally, few studies in Mexico have assessed the effectiveness of psychotherapeutic treatments in such cases (e.g. Sánchez T \& Téllez, 2016) [7].

It is important to understand that sexual abuse is not a disorder or syndrome, but that it can certainly lead to the development of various mental illnesses [8], including PTSD symptoms, sexualized behaviors, depression, anxiety, dissociative conduct disorders and aggressiveness, among others [9-14]. Although sexual abuse in males has been less studied and is likely underestimated compared to females $[15,16]$, there is now considerable evidence of its deleterious effects on the mental health of boys who have experienced this trauma [17-20].

The question of whether therapy for child sexual abuse is harmful, simply ineffective, or unnecessary, is still widely debated [21]. Clinical evaluations and various psychotherapeutic approaches for children who have suffered sexual abuse have been studied extensively in recent years, so today abuse-focused psychotherapy for sexually-abused people is generally deemed beneficial in terms of reducing psychiatric symptoms [22,23]. Another important point is that not all problems -nor all children- respond to treatment [8]. Indeed, it is difficult to determine which young people require therapy because not all sexually-abused children experience serious psychiatric sequelae [24]. In fact, some studies suggest that initially asymptomatic children are those most likely to deteriorate over time $[8,25,26]$. For these reasons, it is crucial to continue testing different treatments and strategies designed to mitigate the effects of the experience of sexual abuse and improve victims' conditions.

Considering reports that evidence of the best efficacy in improving psychological symptoms in sexually-abused children comes from cognitive-behavioral therapy [27,28], the objective of our research was to assess the effectiveness of an individual cognitivebehavioral treatment designed specifically for cases of sexual abuse and its clinical and cognitive sequelae. At the same time, we evaluated two workshops: a group psycho-educational approach and one for the caregivers of two Mexican boys living in an orphanage at the time of study after suffering sexual abuse. Assessments were performed at three points in time: pre-treatment just prior to treatment onset, post-treatment and follow-up one-and-a-half years later.

\section{Method}

\section{Case studies}

Case 1: Juan is a 13-year-old who has lived in the orphanage since he was 10. He lived with his father and mother to age 8 . During those years, he witnessed how his mother subjected his father -who is mute- to continual physical and psychological abuse. Juan has a brother about 7 years older but has almost never lived with him. At present, no one knows of the brother's whereabouts. When Juan was about 4, he witnessed an act of infidelity by his mother with a woman who frequented their home. His mother abandoned the family when Juan was 8, leaving him alone with his father. During that period, he could not attend school because his father always sent him to beg for money to survive, since he had no work. Juan's father abused him sexually with genital contact and penetration almost daily for two years, though this occurred without violence because Juan was afraid of his father and so submitted to his will. At some point, neighbors learned of the situation and reported the case to the authorities, who proceeded to accuse the father and send Juan to an orphanage. The father was sentenced to three years in prison for the crime of sexual abuse. He is now out of jail and wants to see Juan, but while Juan defended him when he entered the home and asked to see him, he now refuses to see him, and the orphanage's authorities are prohibited from allowing contact even though the legal authorities have given permission. Juan's mother will never see him, but a sister of her father who lives in the United States has expressed interest in adopting him. The orphanage's authorities and schoolteachers report that Juan is docile, easy to handle and presents no behavioral problems. However, on one occasion he did steal a considerable amount of money belonging to one of the orphanage's directors and distributed it among several companions.

Case 2: José is a 10-year-old who has lived in the orphanage since age 7. His only brother, who is approximately 6 years older, also lives there. Before their arrival, they lived alone with their mother because their father never accepted responsibility for them. However, she was often absent from the home because of work and left them in the care of her brother. This uncle sexually abused both boys with genital contact, penetration and various types of violence, including tying them up. José and his brother were sent to the orphanage when their mother was accused of negligence and the uncle of sexual abuse, which occurred frequently accompanied by violence for an undetermined period, probably over a year. Neither the mother nor any relatives visit the boys or are interested in adopting or supporting them. The uncle's whereabouts are unknown. Authorities at the orphanage and schoolteachers report that the brothers are docile, easy to handle and do not present behavioral problems. 


\section{Procedure}

Participants and their legal guardians gave their informed consent prior to inclusion. All information related to the history of sexual abuse of the boys was obtained from legal documents. Neither child was questioned directly about the events, but data were corroborated during a psychotherapeutic process that respected the boy's rhythm and willingness to talk about it. Although both children were reticent, they were always available and attended the psychotherapeutic sessions with enthusiasm. Their relationship with the psychotherapist was very good.

\section{Clinical and neuropsychological measures}

All measures were taken in single sessions of approximately one hour held on three occasions: before treatment, immediately after treatment, and one-and-a-half years after the second evaluation. The following assessment tools and scales were applied: the Children's Depression Inventory [29] Spanish version, validated in Mexico by De la Torre [30]; the Trait Anxiety Inventory for Children (STAIC, Spielberg) [31], Spanish version [32]; the Children's Post-Traumatic Stress Scale (CPSS, Foa EB) [33], Spanish version [34]; and selected sub-tests from the Child Neuropsychological Assessment Battery for Spanish-speaking Children (Evaluación Neuropsicológica Infantil, ENI) [35]. Finally, the boys answered the abbreviated version (Vocabulary and Block Design) of the Wechsler Intelligence Scale for Children (WISC-IV-R) to estimate their IQ [36].

\section{Course of treatment}

As mentioned above, both boys were living in an orphanage at the time of study. There, they participated in a group that underwent an initial clinical and neuropsychological evaluation followed by cognitive behavioral treatment that consisted of 24 individual, 30-40 minute sessions once a week for approximately 6 months. Both boys were among the most stable residents in terms of their situation in the orphanage and permanence in this process, despite frequent personnel changes in the institution.

The individual Cognitive-Behavioral Therapy program was based on elements recommended for treating post-traumatic stress [37] and sexual abuse [38], though the order of the sessions and some points of treatment were suggested by the authors of this study. Therapeutic components utilized included free and directed games, stories, drawings, the impact of stress on the body, emotions and mind, work on nightmares, relaxation training, talking and drawing images of thoughts, feelings and emotions, describing people with whom they live and themselves, family roles, problem-solving, revisiting the site of the trauma, distinguishing reality from fiction, discussing what to do in the face of threats, and exercises in self-awareness. All evaluations and treatment sessions for both participants were conducted by the same psychologist, who has ample experience working with traumatized children.

In addition, the two boys participated in a psycho-educational workshop on information, prevention and support for victims of sexual abuse. This was directed by two psychologists assisted by some psychology students. It consisted of 12 weekly sessions of approximately one-and-a-half hours each. The second workshop focused on strategies for working with children and adolescents who have experienced abuse. It included 18 weekly sessions of two hours each and was aimed at the children's caregivers. Both workshops were conducted during the same period as the individual psychotherapy.

\section{Results}

\section{Clinical and neuropsychological tests}

On the CDI test, neither participant had significant scores for depression on the three evaluations, where scores of 19 or higher indicate depressive symptoms. The STAIC test classifies respondents who achieve scores below 40 as having a low level of anxiety traits, while scores above 60 are classified as showing high anxiety. Both boys presented medium levels for trait anxiety on the first evaluation. Only José showed medium levels for trait anxiety on the second assessment, but neither boy presented significant levels of anxiety on the third. To judge the presence of PTSD, the criteria from the Diagnostic and Statistical Manual of Mental Disorders (DSM-IV) were applied to detect the following symptoms: at least 1 of re-experiencing, 3 of avoidance, and 2 of increased activation [39], considering the index of PTSD symptoms according to the event of sexual abuse. Subsyndromal PTSD was defined following

\begin{tabular}{|c|c|c|c|c|c|c|}
\hline \multirow{2}{*}{$\begin{array}{l}\text { Clinical } \\
\text { Scales }\end{array}$} & \multicolumn{2}{|c|}{ Pre-treatment } & \multicolumn{2}{|c|}{ Post-treatment } & \multicolumn{2}{|c|}{$\begin{array}{l}1 \text { year-and-a-half } \\
\text { follow-up }\end{array}$} \\
\hline & \multicolumn{6}{|c|}{ Scores } \\
\hline $\begin{array}{c}\text { Children's Depression } \\
\text { Inventory (CDI) }\end{array}$ & Case 1 & Case 2 & Case 1 & Case 2 & Case 1 & Case 2 \\
\hline $\begin{array}{l}\text { Anxiety Inventory for } \\
\text { Children (STAIC) }\end{array}$ & 6 & 10 & 6 & 12 & 0 & 12 \\
\hline \multirow[t]{4}{*}{$\begin{array}{c}\text { Children's Post-traumatic } \\
\text { Symptoms Stress Scale } \\
\text { (CPSS) }\end{array}$} & $33 \mathrm{~s}^{*} / 41 \mathrm{t}^{* *}$ & $33 \mathrm{~s} / 40 \mathrm{t}$ & $37 \mathrm{~s} / 30 \mathrm{t}$ & $35 \mathrm{~s} / 40 \mathrm{t}$ & $22 \mathrm{~s} / 22 \mathrm{t}$ & $39 \mathrm{~s} / 31 \mathrm{t}$ \\
\hline & $1 \mathrm{r} \bullet$ & $5 r$ & $3 r$ & $3 r$ & $3 r$ & $3 r$ \\
\hline & & 4a.• & la & $2 \mathrm{k}$ & 1a & $2 \mathrm{k}$ \\
\hline & & $7 \mathrm{k} \bullet . \bullet$ & & & & \\
\hline
\end{tabular}

${ }^{*} \mathrm{a}=$ State anxiety; ${ }^{* *} \mathrm{t}=$ Trait anxiety; $\bullet \mathrm{r}=$ Reliving symptoms; $\bullet \bullet \mathrm{a}=$ Avoiding symptoms; $\bullet \bullet \bullet \mathrm{k}=$ Keyed up symptoms

Table 1: Summary of the clinical symptoms of the two participants on the three evaluations 
[39], who consider the minimum number of symptoms for the re-experiencing criterion and meeting either the avoidance or the hyper-arousal criterion. Although Juan's scores on the CPSS scale were not significant on any of the three evaluations, they did increase on the second and third occasions, especially in relation to symptoms of reliving. José, in contrast, presented signs of PTSD on the first evaluation and of subsyndromal PTSD on assessments two and three (Table 1). Juan's IQ score actually increased on the second and third evaluations compared to the first one, while Josés level remained virtually identical on the first and second evaluations but decreased on the third. There was no pattern of improvement or worsening in the scores on the attention and memory subtests in either participant, though both showed a certain upwards tendency on evaluations two and three (Table 2).

\begin{tabular}{|c|c|c|c|c|c|c|}
\hline \multirow{3}{*}{ Cognitive assessment } & \multicolumn{2}{|c|}{ Pre-treatment } & \multicolumn{2}{|c|}{ Post-treatment } & \multicolumn{2}{|c|}{$\begin{array}{l}1 \text { year-and-a-half } \\
\text { follow-up }\end{array}$} \\
\hline & \multicolumn{6}{|c|}{ Scores } \\
\hline & Case 1 & Case 2 & Case 1 & Case 2 & Case 1 & Case 2 \\
\hline \multicolumn{7}{|l|}{ Visual attention* } \\
\hline Cancellation of drawings & 5 & 0.1 & 9 & 9 & 5 & 16 \\
\hline Letter cancellation & 0.1 & 0 & 9 & 16 & 26 & 37 \\
\hline \multicolumn{7}{|l|}{$\begin{array}{l}\text { Auditory attention and } \\
\text { working memory }\end{array}$} \\
\hline Forward digit span & 16 & 5 & 50 & 37 & 2 & 50 \\
\hline Backward digit span & 5 & 26 & 26 & 91 & 26 & 5 \\
\hline \multicolumn{7}{|l|}{ Auditory verbal memory ${ }^{\star}$} \\
\hline Word List & 0.1 & 0.4 & 1 & 50 & 16 & 37 \\
\hline Test memory & 1 & 0 & 1 & 16 & 2 & 2 \\
\hline $\mathrm{IQ}^{\star *}$ & 76 & 82 & 82 & 84 & 82 & 70 \\
\hline
\end{tabular}

${ }^{*}$ Child Neuropsychological Assessment, Battery for Spanish-speaking Children. Scores were converted to percentiles.

Values are as follows: Extremely low $=\leq 2$; Low= 3-10; Low average $=11-25$; Average $=26-75$; Above average $=>75$.

${ }^{* *}$ Vocabulary and block design subsets of the Wechsler Intelligence Scale for Children (WISC-IV-R).

Table 2: Cognitive and IQ scores of the two participants on the three evaluations

\section{Discussion}

This study presents an evaluation of the effectiveness of a psychotherapeutic treatment tested on two Mexican male children who were victims of sexual abuse. Results indicate that the boys had some significant differences in their scores on the three clinical and neuropsychological evaluations conducted despite similarities in their respective histories; for example, both are male, experienced sexual abuse at an early age, and live away from their parents in the same orphanage. On the pre-treatment evaluation, Juan appeared to be asymptomatic. The effectiveness of the individual cognitive-behavioral treatment, the psycho-educational workshop, and the workshop for caregivers applied in this study was not reflected in any clear or specific manner in the two subjects. Despite reports that cognitive-behavioral therapy is effective in reducing symptoms of PTSD secondary to sexual abuse [40-43], the results of the present study show that only José experienced a reduction of PTSD symptoms, though they continued to be clinically significant. In contrast, Juan's symptoms increased after psychotherapy, since on the first evaluation he presented only one symptom. This result may have occurred because he became more aware of the traumatic event he had suffered, since it has been suggested that children who manifest patterns of denial and avoidance have more difficulty in recovering and are less active during treatment [44]. These patterns of behavior -denial and avoidance- are very common in Mexico, especially in males, due to the factors like the following: rape brings shame to the family; social problems related to sex and sexuality tend to be silenced and stigmatized; most sexual abuse victims tend to experience shame, which is culturally-defined because gender behaviors, expectations and sexual practices are socially-constructed; and when children disclose their abuse they are often questioned and rejected by relatives and family members who refuse to believe them [6].

Juan presented a decrease in depressive symptoms and anxiety on the two post-treatment evaluations; however, his initial scores were clinically insignificant, so it is difficult to determine whether this decrease: (1) reflects a possible positive effect of treatment; (2) was simply a result of the passing of time; (3) was due to him being away from the perpetrator; or (4) resulted from his interaction with other kinds of people in the milieu of the orphanage to which he had adapted. With respect to José, his scores on these measures remained virtually the same on all three evaluations, with only a slight improvement in anxiety levels posttreatment.

The lack of clarity in the effectiveness of the treatment regimen applied in this study may be due to the content, structure and associated characteristics of the approach adopted and the workshops, and factors proposed in previous research, such as the precise nature of the traumatic experience, the degree of traumatization suffered [45], and specific features or characteristics of the victims [23]. In Mexican culture, part of being male means minimizing, or even completely ignoring, the damage that others may inflict. The phrase "Men don't cry" is often heard there, and people believe that experiences of sexual abuse are best trivialized and swept under the carpet, though this may severely affect both the evaluation process and the treatment that could be offered. 
The main traits that our two participants share are being male, experiencing sexual abuse with genital contact and penetration at a young age, being neglected by both parents, having only one older brother, and presenting docile behavior, submission to authorities, and acceptable levels of social and scholastic performance. The main differences are: Juan was abused sexually by his father, to whom he felt great attachment, and the abuse occurred without too much force, though it was more frequent and went on longer, while José was abused by an uncle with whom he felt no great attachment and suffered much more violence during the abuse. Though it has been suggested that incestuous experiences are more traumatic than abuse committed by other family members [9,46], in our study José manifested more symptoms and intense PTSD, perhaps reflecting the fact that his experience of sexual abuse included the use of force, another variable strongly-related to deleterious impacts on mental health [47]. Another difference is that José was younger than Juan when the abuse happened, a fact that might influence the presence and persistence of symptoms, since there are indications that some periods of childhood development are particularly sensitive to the effects of such abuse [48]. Moreover, studies have demonstrated a relationship between early age and trauma [9]. Finally, Juan was seen to seek more approval from his peers and authorities through various acts, including stealing to give something to others. This may be because his father left him with the obligation to maintain the home at all costs while they lived together. Perhaps in part because of this, José is more passive.

Another reason why the treatment applied in this study did not produce clearer results could be because the boys live in an orphanage where changes of personnel are frequent and there is no established model of discipline. Thus, there is no specific attachment figure that could provide protective factors for their life experiences, as has been suggested elsewhere [49].

Although this study does not present clear or definitive results regarding the efficacy of the treatment applied, we believe it provides sufficient evidence that various psychotherapeutic treatments can be effective in improving psychiatric symptoms and other qualitative aspects in people who have experienced sexual abuse. However, we also believe that it is crucial to continue investigating key aspects of the treatment of sexual abuse.

While the present treatment was organized and applied in a systematic manner that took into account important details related to the sequelae of sexual abuse and the environment surrounding participants, this proved insufficient to achieve clear improvement in their clinical symptoms and neuropsychological functioning. This may indicate, among other possibilities, that the individual therapy and workshops applied were not appropriate, or were insufficient, for achieving the study's objectives.

\section{Conclusion}

Despite the limitations of this research, the three assessments of the participants suggest that it is not easy to carry out an adequate evaluation and treatment in cases of sexual abuse, since it is difficult to determine, in the first instance, the victim's specific, general and particular needs. However, some key indicators of changes in their attitudes and symptoms related to the psychotherapeutic process suggest that the attention provided conferred more advantages than disadvantages. Also, studies of this kind indicate the need to continue studying -and perhaps modifying- the content and structure of interventions.

Finally, it may be that greater environmental support is needed in relation to certain key elements if interventions of this nature are to achieve improvement in the short, medium, and long terms.

\section{References}

1. World Health Organization (1999) Report of the Consultation on Child Abuse Prevention, Geneva, Sweden.

2. Pereda N, Guilera G, Forns M, Gómez-Benito J (2009) The prevalence of child sexual abuse in community and student samples: A meta-analysis. Clin Psychol Rev 29: 328-38.

3. Ramos-Lira L, Saldívar-Hernández G, Medina-Mora ME, Rojas-Guiot E, Villatoro-Velázquez J (1998) Prevalencia de abuso sexual en estudiantes y su relación con el consumo de drogas. Salud Pública Mex 40.

4. Chávez Ayala R, Rivera-Rivera L, Angeles-Llerenas A, Díaz-Cerón E, Allen-Leigh B, et al. (2009) Factores del abuso sexual en la niñez y la adolescencia en estudiantes de Morelos, México. Rev Saúde Pública 43: 506-14.

5. Pineda Lucatero AG, Trujillo Hernández B, Millán Guerrero RO, Vásquez C (2009) Prevalence of childhood sexual abuse among Mexican adolescents. Child Care Health Dev 35: 184-9.

6. Frías SM, Erviti J (2014) Gendered experiences of sexual abuse of teenagers and children in Mexico. Child Abuse Negl 38: 776-87.

7. Sánchez T, Téllez A (2016) Hipnoterapia y terapia breve centrada en soluciones aplicada a síntomas por abuso sexual infantil: Un estudio de caso. Revista de Psicopatología y Psicología Clínica 21: 67-75.

8. Finkelhor D, Berliner L (1995) Research on the treatment of sexually abused children: A review and recommendations. J Am Acad Child Adolesc Psychiatry 34: 1408-23.

9. Browne A, Finkelhor D (1986) Impact of child sexual abuse: a review of the research. Psychol Bull 99: 66-77.

10. Bagley C (2009) The prevalence and mental health sequels of child sexual abuse in a community sample of women aged 18 to 27. Can J Commun Ment Health 10: 103-16.

11. Dutton DG, Hart SD (1992) Evidence for long-term, specific effects of childhood abuse and neglect on criminal behavior in men. Int Offender Ther Comp Criminol 36: 129-37.

12. McLeer SV, Callaghan M, Henry D, Wallen J (1994) Psychiatric disorders in sexually abused children. J Am Acad Child Adolesc Psychiatry 33: $313-9$.

13. Paolucci EO, Genuis ML, Violato C (2001) A meta-analysis of the published research on the effects of child sexual abuse. The Journal of psychology 135: 17-36. 
14. Cheasty M, Clare AW, Collins C (1998) Relation between sexual abuse in childhood and adult depression: case-control study. Bmj 316: 198-201.

15. Diamanduros T, Cosentino CE, Tysinger PD, Tysinger JA (2012) Theoretical perspectives of male sexual abuse: conceptualization of a case study. J Child Sex Abus 21: 131-54.

16. Holmes GR, Offen L, Waller G (1997) See no evil, hear no evil, speak no evil: Why do relatively few male victims of childhood sexual abuse receive help for abuse-related issues in adulthood? Clin Psychol Rev 17: 69-88.

17. Romano E, De Luca RV (2001) Male sexual abuse: A review of effects, abuse characteristics, and links with later psychological functioning. Aggress Violent Behav 6: 55-78.

18. Dhaliwal GK, Gauzas L, Antonowicz DH, Ross RR (1996) Adult male survivors of childhood sexual abuse: Prevalence, sexual abuse characteristics, and longterm effects. Clin Psychol Rev 16: 619-39.

19. Holmes WC, Slap GB (1998) Sexual abuse of boys: Definition, prevalence, correlates, sequelae, and management. Jama 280: $1855-62$.

20. Fontanella C, Harrington D, Zuravin SJ (2000) Gender differences in the characteristics and outcomes of sexually abused preschoolers. J Child Sex Abus 9: 21-40.

21. Oellerich TD (2001) Child sexual abuse: Is the routine provision of psychotherapy warranted. IPT Journal 11.

22. Martsolf DS, Draucker CB (2005) Psychotherapy approaches for adult survivors of childhood sexual abuse: An integrative review of outcomes research. IIssues Ment Health Nurs 26: 801-25.

23. Trask EV, Walsh K, DiLillo D (2011) Treatment effects for common outcomes of child sexual abuse: A current meta-analysis. 『Aggress Violent Behav 16: 6-19.

24. Putnam FW (2003) Ten-year research update review: Child sexual abuse. J Am Acad Child Adolesc Psychiatry 42: 269-78.

25. Mannarino A, Cohen J, Smith J, Moore-Motily (1991) Six and twelve month follow-up of sexually abused girls. J Interpers Violence 6: 494-511.

26. Gomes-Schwartz B, Horowitz J, Carcharelli A (1990) The aftermath of child sexual abuse 18 months later In: Child Sexual Abuse, Newbury Park, CA: Sage, USA.

27. Ramchandani P, Jones DP (2003) Treating psychological symptoms in sexually abused children. Br J Psychiatry 183: 484-90.

28. Deblinger E, Stauffer LB, Steer RA (2001) Comparative efficacies of supportive and cognitive behavioral group therapies for young children who have been sexually abused and their nonoffending mothers. Child Maltreatment 6: 332-43.

29. Kovacs M (1992) Children Depression Inventory CDI (Manual). Toronto: Multihealth Systems.

30. de la Torre IM, Álvarez JFL, Chávez-Hernández AM, Godoy SAS, Soto NYT (2016) Propiedades psicométricas del CDI en una muestra no clínica de niños de la ciudad de Hermosillo, México. Psicología y Salud 26: 273-82.

31. Spielberg CD (1983) Manual for the State-Trait Anxiety Inventory. Consulting Psychologists Press, Palo Alto.

32. Castrillón Moreno DA, Borrero Copete PE (2005) Validación del inventario de ansiedad estado-rasgo (STAIC) en niños escolarizados entre los 8 y 15 años. Acta colombiana de psicología 8: 79-90.

33. Foa EB, Johnson KM, Feeny NC, Treadwell KR (2001) The Child PTSD Symptom Scale: A preliminary examination of its psychometric properties. J Clin Child Adolesc Psychol 30: 376-84.

34. Bustos P, Rincón P, Aedo J (2009) Preliminary Validation of the Child PTSD Symptom Scale (CPSS) in Children and Adolescent Victims of Sexual Violence. Psykhe 18: 113-26.

35. Matute E, Rosselli M, Ardila A, Ostrosky-Solís F (2007) Evaluación neuropsicológica infantil. México: Manual Moderno.

36. Wechsler D (1991) Wechsler Inteligence scale for children. San Antonio, TX: The Psychological Corporation, Third Google Scholar.

37. Shein KJ (2013) Terapia para estrés postraumático: aplicada a jóvenes de 12 a 18 años. Editorial Trillas.

38. Lammoglia E (1999) Abuso sexual en la infancia: Cómo prevenirlo y superarlo, Grijalbo publisher, Mexico.

39. Blanchard EB, Hickling EJ, Barton KA, Taylor AR, Loos WR, et al. (1996) One-year prospective follow-up of motor vehicle accident victims. Behav Res Ther 10: $775-86$.

40. McDonagh A, Friedman M, McHugo G, Ford J, Sengupta A, et al. (2005) Randomized trial of cognitive-behavioral therapy for chronic posttraumatic stress disorder in adult female survivors of childhood sexual abuse. J Consult Clin Psychol 73: 515-24.

41. Deblinger E, Steer RA, Lippmann J (1999) Two-year follow-up study of cognitive behavioral therapy for sexually abused children suffering post-traumatic stress symptoms. Child Abuse Negl 23: 1371-378.

42. Deblinger E, McLeer SV, Henry D (1990) Cognitive behavioral treatment for sexually abused children suffering post-traumatic stress: Preliminary findings. J Am Acad Child Adolesc Psychiatry 29: 747-52.

43. Deblinger E, Lippmann J, Steer R (1996) Sexually abused children suffering posttraumatic stress symptoms: Initial treatment outcome findings. Child Maltreatment 1: 310-21.

44. Larzelere RE, Collins LE, Collins RA (1994) Effectiveness of group treatment for sexual abuse by PTSD symptoms In: Annual Convention of the International Society for Traumatic Stress Studies. Chicago, USA.

45. Finkelhor D, Browne A (1985) The traumatic impact of child sexual abuse: a conceptualization. Am J Orthopsychiatry 55: 530-41.

46. Russell D (1986) The secret trauma: Incest in the lives of women and girls.

47. Beitchman JH, Zucker KJ, Hood JE, DaCosta GA, Akman D, et al. (1992) A review of the long-term effects of child sexual abuse. Child Abuse Negl 16: 101-18. 48. Andersen SL, Tomada A, Vincow, ES, Valente E, Polcari A, et al. (2008) Preliminary evidence for sensitive periods in the effect of childhood sexual abuse on regional brain development. J Neuropsychiatry Clin Neurosci 20: 292-301.

49. Rutter M (1985) Resilience in the face of adversity. Protective factors and resistance to psychiatric disorder. Br J Psychiatry 147: 598-611.

50. American Psychiatric Association (2000) Diagnostic and statistical manual of mental disorders (4th ed text rev). Washington, DC: American Psychiatric Association.

51. Friedrich WN (1995) Managing disorders of self-regulation in sexually abused boys. In M. Hunter (Ed) Child survivors and perpetrators of sexual abuse: Treatment innovations. Thousand Oaks, CA: Sage Publications. 


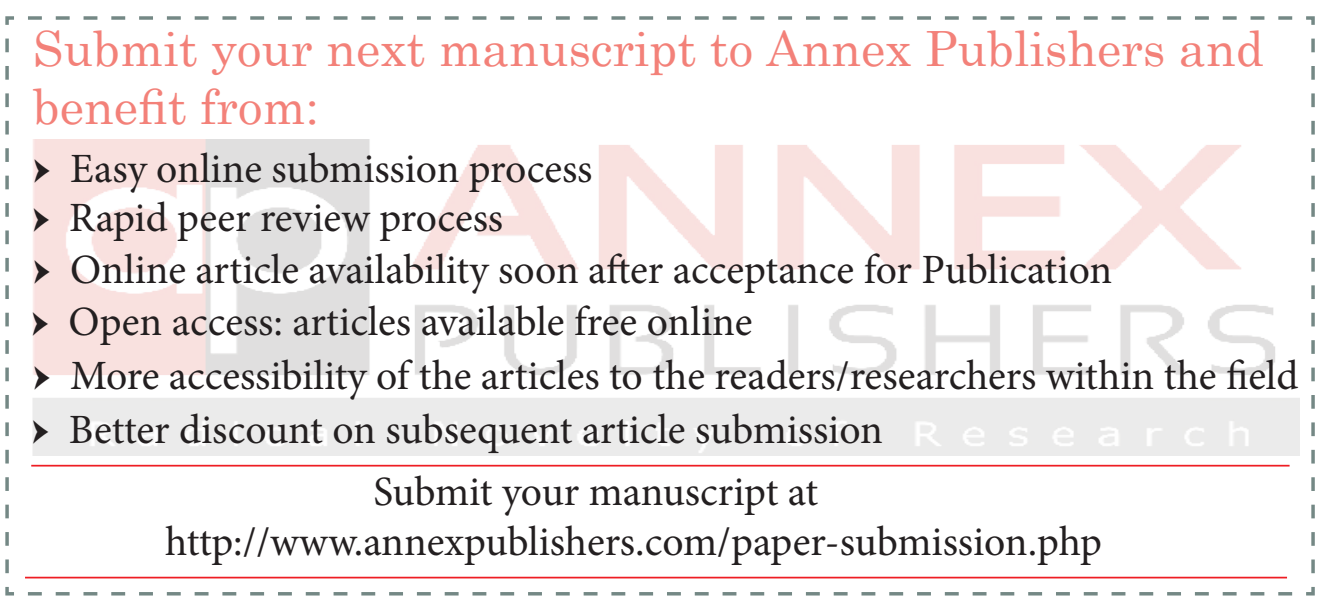

